\title{
Genetic screening for autosomal recessive nonsyndromic mental retardation in an isolated population in Israel
}

\author{
Lina Basel-Vanagaite ${ }^{* 1,2}$, Ellen Taub ${ }^{1}$, Gabrielle J Halpern ${ }^{1}$, Valerie Drasinover ${ }^{3}$, \\ Nurit Magal ${ }^{3}$, Bella Davidov ${ }^{1}$, Joël Zlotogora ${ }^{4}$ and Mordechai Shohat ${ }^{1,2,3}$
}

\begin{abstract}
${ }^{1}$ Department of Medical Genetics, Rabin Medical Center, Beilinson Campus, Petah Tikva; ${ }^{2}$ Sackler Faculty of Medicine, Tel Aviv University, Tel Aviv; ${ }^{3}$ Felsenstein Medical Research Center, Rabin Medical Center, Petah Tikva; ${ }^{4}$ Department of Community Genetics, Ministry of Health and Hadassah Medical School Hebrew University, Jerusalem, Israel
\end{abstract}

Nonsyndromic mental retardation (NSMR) is the diagnosis of exclusion in mentally retarded individuals without additional abnormalities. We have recently identified a protein-truncating mutation, G408fsX437, in the gene CC2D1A on chromosome 19p13.12 in nine consanguineous Israeli Arab families with severe autosomal recessive NSMR, and have developed a comprehensive prevention program among the at-risk population in the village. The subjects tested were healthy women who were invited to undergo the genetic screening test as a part of their routine pregnancy monitoring. One hundred and seventeen subjects reported a family history positive for mental retardation. We tested 524 pregnant or preconceptional women and found 47 carriers $(\sim 1 / 11)$, whose spouses were then recommended to undergo testing. We identified eight carrier couples, who were given genetic counseling and offered prenatal diagnosis. Of all the marriages, $28.6 \%$ were consanguineous; $16.5 \%$ of the total were between first cousins. The high prevalence of the mutation can be explained both by the founder effect owing to the generally high consanguinity rate among the inhabitants of the village, and also because two families with excessive numbers of mentally retarded offspring were unacceptable as marriage partners by the rest of the families. This is the first example of the establishment of a large-scale genetic screening program for autosomal recessive NSMR, which was made possible owing to the high frequency of the specific causative mutation in this isolated population.

European Journal of Human Genetics (2007) 15, 250-253. doi:10.1038/sj.ejhg.5201750; published online 6 December 2006

Keywords: mental retardation; screening; CC2D1A; carriers; prenatal diagnosis; consanguinity

\section{Introduction}

Mental retardation affects approximately 1 to $3 \%$ of the general population. ${ }^{1,2}$ Genetic etiologies are found in approximately two thirds of mental retardation cases. ${ }^{3}$

${ }^{*}$ Correspondence: Dr Lina Basel-Vanagaite. Department of Medical Genetics, Rabin Medical Center, Beilinson Campus, Petah Tikva 49100, Israel.

Tel: + 9723937 7659; Fax: +97239377660.

E-mail: basel@post.tau.ac.il

Received 6 June 2006; revised 31 August 2006; accepted 20 October 2006; published online 6 December 2006
Nonsyndromic mental retardation (NSMR) is the diagnosis of exclusion in mentally retarded individuals who do not have major physical abnormalities, dysmorphism or neurological abnormalities. Biological processes involved in neuronal differentiation and synaptic plasticity, synaptic vesicle cycling and gene expression regulation are considered to be important in the causation of mental retardation. ${ }^{4}$

An autosomal recessive mode of inheritance may account for nearly a quarter of all individuals with NSMR. $^{5-7}$ Only two autosomal genes, the PRSS12 gene 
on chromosome 4q26 [MIM 606709] and the CRBN gene on chromosome 3p26 [MIM 607417], have been shown to cause autosomal recessive NSMR, each gene in only one family. ${ }^{8,9}$

Autosomal recessive diseases are common in the Arab population of Israel, mostly as a result of the high rate of consanguinity. Among Israeli Arabs, up to 44\% of the marriages used to be between relatives, approximately half of which were between first cousins, although these numbers are somewhat lower today. ${ }^{10,11}$ In these communities rare autosomal recessive diseases are relatively frequent and can be limited to one village. ${ }^{12}$ Identifying the molecular basis of severe genetic conditions may allow for genetic counseling and genetic screening, and therefore may greatly reduce the number of affected infants born.

We have recently identified a protein-truncating mutation in the gene CC2D1A on chromosome 19p13.12 in nine consanguineous Israeli Arab families with severe autosomal recessive NSMR who live in an isolated village in central Israel. ${ }^{13}$ In the current study; we screened a large unselected sample of the residents of this village for the mutation G408fsX437 in the CC2D1A gene. We have developed a strategy for a comprehensive mental retardation prevention program in this community.

\section{Materials and methods Subjects}

The screening was performed in a Muslim Israeli Arab village of 10500 inhabitants, who can be grouped into 20 clans of various origins. Among the village founders were families whose ancestors migrated from Sudan and descendents of families who came to Palestine from Egypt along with Muhammad Ali's troops in 1834.

Only married couples in which both spouses were born in the village were referred for screening. The women were seen at the women's health station in the village and genetic counseling was provided by the same medical geneticist and genetic counselor. The subjects of this study were women visiting the women's health station either for routine pregnancy monitoring or for a routine examination of their child. An extensive family pedigree going back three generations was constructed for each person tested. Data regarding family history of mental retardation were obtained by interviewing the women and the nurses and examining the files at the women's health station. Blood was drawn during the same session and was taken to the hospital where the DNA study was performed.

The screening program including genetic counseling and testing was provided free of charge, financed by the Israeli Ministry of Health as part of a program designed towards the prevention of frequent genetic diseases in Israel. All the individuals who were found to be carriers of the G408fsX437 mutation in the CC2D1A gene were offered genetic counseling in which genetic testing of their spouses was recommended. Carrier couples were given genetic counseling and were offered the possibility of free prenatal diagnosis either bychorionic villus sampling (CVS) or amniotic fluid analysis.

\section{Mutation analysis}

During the years 2003 and 2004, before the identification of the gene, carrier detection was performed by analysis of polymorphic markers that were known to be in linkage disequilibrium with the disease-causing gene. ${ }^{13}$ Markers D19S840, RFX1 and D19S1420 were analyzed (primers available on request). Individuals carrying all three alleles characteristic to the disease haplotype were considered carriers. After the discovery of the disease gene, all those defined as carriers were retested for the CC2D1A G408fsX437 mutation.

From the year 2005 onwards, G408fsX437 mutation genotyping was performed on genomic DNA by PCR using the following primers: for normal alleles: forward primer: ttggtctccatcctgacaca, reverse primer: tcccaaagtgctgggactac; for mutant alleles: forward primer: gggagcttgacattggacat, reverse primer: ggggtaaggaggacaagcag.

\section{Results \\ Carrier screening}

Between March 2003 and January 2006, a total of 524 pregnant or preconceptional women and 14 male spouses were tested. Six women reported having children with developmental delay or mental retardation and 117 individuals reported a family history positive for mental retardation. Three hundred and seventy-four of those examined denied consanguinity, whereas in 150 couples the spouses were related; the relationships are shown in Table 1 . In all, $28.6 \%$ of the marriages were consanguineous; $58 \%$ of these ( $16.5 \%$ of the total) were between first cousins.

Among the 524 women screened, 47 carriers were diagnosed $(\sim 1 / 11)$. Out of the 47 spouses, only 14 came to be tested, and eight of these were found to be carriers. Among the eight carrier couples detected, six had children

Table 1 Relationships of the spouses in the couples examined

\begin{tabular}{lcr}
\hline Relationship of spouses & Numbers & Percent \\
\hline Double first cousins & 6 & 1.1 \\
First cousins (other than double) & 81 & 15.5 \\
First cousins once removed & 15 & 2.9 \\
Second cousins & 32 & 6.1 \\
Second cousins once removed & 1 & 0.2 \\
Third cousins & 2 & 0.4 \\
More distantly related & 13 & 2.5 \\
Not related & 374 & 71.3 \\
Total & 524 & 100 \\
\hline
\end{tabular}


Table 2 Prenatal diagnostic procedures (CVS) performed in the carrier couples

\begin{tabular}{lllccc}
\hline $\begin{array}{l}\text { Carrier couple } \\
\text { number }\end{array}$ & $\begin{array}{l}\text { Relationship } \\
\text { between spouses }\end{array}$ & $\begin{array}{l}\text { Previous affected } \\
\text { children (number) }\end{array}$ & $\begin{array}{c}\text { Number of } \\
\text { pergnancies }\end{array}$ & $\begin{array}{c}\text { Number of CVSs } \\
\text { performed }\end{array}$ & Result of prenatal diagnosis \\
\hline 1 & Not related & Yes (1) & 1 & 1 & Unaffected \\
2 & First cousins & No & 1 & 1 & Unaffected \\
3 & First cousins & Yes (1) & 1 & 1 & Affected - pregnancy terminated \\
4 & Not related & Yes (1) & 1 & 1 & Unaffected \\
6 & First cousins & Yes (2) & 2 & 2 & Both unaffected - aborted \\
spontaneously & Prenatal diagnosis not performed \\
7 & First cousins & No & 1 & 0 & - \\
5 & Second cousins & Yes (2) & 0 & 0 & - \\
8 & First cousins once & Yes (3) & 0 & 0 & - \\
\hline
\end{tabular}

with MR or developmental delay, all of whom were homozygous for the G408fsX437 mutation, and two had no affected children. In one additional couple the husband reported a positive family history for mental retardation. Five of the eight carrier couples identified during pregnancy underwent prenatal diagnosis. In one of these couples the woman was also tested during her subsequent pregnancy. In a total of six prenatal diagnostic procedures performed one pregnancy of an unaffected fetus ended as a spontaneous abortion and one pregnancy with an affected fetus was terminated (Table 2). All the four children who were diagnosed prenatally as unaffected are developing normally.

\section{Discussion}

The relatively high frequency of mental retardation in the village has been known for decades and because of the high heterogeneity of this condition it was thought that it may be owing to different causes. Thus the finding that most cases of mental retardation in the village are secondary to a single cause was unexpected. We have identified in total twelve families with mentally retarded children. Six of the families were known to us previously from the research, and a further six were identified through the genetic screening program in the village. The screening program revealed a carrier frequency of $\sim 1 / 11$ among individuals born in the village, consistent with the high frequency of the disorder.

All the carriers belong almost exclusively to the two families whose ancestors migrated from Sudan in the 19th century, and the mutation was not found in members of other families in the village. This means that the mutation must have occurred in a common ancestor of these two families before they settled in the village, which was over 150 years ago. In Israel today there are more than 10000 Arabs whose African ancestors came to Israel mostly during the nineteenth century. Arab merchants sold them as slaves to rich Arab landowners and Bedouin tribal chiefs. In time, the Africans converted to Islam and adopted the Arabic language.
It may be inferred that the basis of the high frequency of the mutation is mainly a founder effect resulting from the high rates of intermarriage among the members of these two families. An additional reason for the very high carrier rate is that these same two extended families have a large number of mentally retarded individuals, and therefore members of other families are unwilling to marry into these two families. As a result, the members of these families have no choice other than to marry among themselves.

Among Muslims, there are several opinions as to whether elective abortion may be allowed if the fetus is affected with a severe condition, but in all cases this must be before the $120^{\text {th }}$ day of the pregnancy. Although among Muslims in Israel fewer than 30\% of women at risk for Down's syndrome undergo prenatal diagnostic testing, ${ }^{14}$ early prenatal testing by CVS for monogenic disorders such as thalassemia is well accepted. ${ }^{15,16}$ This may be explained by differences in the perceived severity of the type of disorders and the possibility of early diagnosis at a stage when termination is still permissible according to religion and tradition. ${ }^{16}$ Therefore it may be expected that with the possibility of detection of at-risk couples in the village there will be a significant reduction in the number of births of mentally retarded children as long as the prenatal diagnosis is carried out early in the pregnancy.

An extremely important part of any genetic screening program is the availability of appropriate genetic counseling. The benefits of undergoing a genetic test are not limited to the woman's current pregnancy but are also relevant for all her subsequent pregnancies. In addition, if a mutation carrier is identified, genetic counseling should be offered not only to the individual carrier, but also to any relatives who might be at risk. However, the problem of such cascade screening in a closed population is that medical information must be revealed, interfering with privacy. In this village, as in the Muslim population of Israel generally, there is secrecy about genetic diseases. Carrying out general screening of all the couples in the population allows for a similar result as cascade screening 
in a closed population without revealing any information about carriers.

As already described, it was decided that the first stage of the program would include only married couples in the setting of the mother and child stations, and therefore this would be carried out mainly during pregnancy when the women came for routine pregnancy monitoring. In the cases where the husbands were invited for examination the compliance was relatively low. The men gave various reasons why they were reluctant or unable to attend, one of which was that they did not want to take time off work to come to the health station during the morning hours. Another was that the men did not wish to go to the women's health station as this was a place 'only for women'. It is interesting that compliance was higher among males with a positive family history of mental retardation - this is probably due to the fact that these men were far more aware than those without such a family history of the possible consequences of carrier status and were therefore more willing to be tested. The advantage of preconceptional genetic screening is that it allows for more time for genetic counseling and reproductive decision-making in mutation carriers. On the other hand, such screening is difficult in practice, especially in populations living far away from the hospital where the genetic tests are performed. It is expected that with time, increasing knowledge about the screening, the availability of genetic counseling and the drawing of the blood within the village itself, more couples will come for consultation before their first pregnancy or even before marriage. The aim is that the at-risk couples will have information about their status and risks before a pregnancy so that they can better plan their reproductive life.

Mental retardation is a serious burden for families and society. Comprehensive screening for detection of fetuses with Down's syndrome is offered in Israel as well as in many other countries. Recently there have been some attempts at screening for fragile $\mathrm{X}$ syndrome, and in Israel this is offered as a private service. ${ }^{17}$ In the case of NSMR there is no large-scale prevention program because of its heterogeneity and to the best of our knowledge this is the first example of the establishment of a large-scale prevention program for autosomal recessive NSMR. Until high-throughput molecular diagnostic technologies for highly heterogeneous conditions become available, identification of the specific genes in appropriate populations will enable the development of a genetic service aimed at effective prevention of mental retardation.

\section{Acknowledgements}

We are grateful to the families who participated in this study and clinical nurses Hitam, Inshirah, Sylvia, Shiraz and Fatma. This study was funded by the Yeshaya Horovitz grant for Neurogenetics research and the Israeli Science Foundation (grant No 690/04).

\section{References}

1 McLaren J, Bryson SE: Review of recent epidemiological studies of mental retardation: prevalence, associated disorders, and etiology. Am J Ment Retard 1987; 92: 243-254.

2 Leonard $\mathrm{H}$, Wen X: The epidemiology of mental retardation: challenges and opportunities in the new millennium. Ment Retard Dev Disabil Res Rev 2002; 8: 117-134.

3 Curry CJ, Stevenson RE, Aughton D et al: Evaluation of mental retardation: recommendations of a consensus conference: American College of Medical Genetics. Am J Med Genet 1997; 72: $468-477$.

4 Renieri A, Pescucci C, Longo I, Ariani F, Mari F, Meloni I: Nonsyndromic X-linked mental retardation: From a molecular to a clinical point of view. J Cell Physiol 2005; 204: 8-20.

5 Wright SW, Tarjan G, Eyer L: Investigation of families with two or more mentally defective siblings: clinical observations. Am J Dis Child 1959; 97: 445-456.

6 Priest JH, Thuline HC, Laveck GD, Jarvis DB: An approach to genetic factors in mental retardation. Studies of families containing at least two siblings admitted to a state institution for the retarded. Am J Ment Defic 1961; 66: 42-50.

7 Bartley JA, Hall BD: Mental retardation and multiple congenital anomalies of unknown etiology: frequency of occurrence in similarly affected sibs of the proband. Birth Defects Res Clin Mol Teratol 1978; 14: 127-137.

8 Molinari F, Rio M, Meskenaite V et al: Truncating neurotrypsin mutation in autosomal recessive nonsyndromic mental retardation. Science 2002; 298: 1779-1781.

9 Higgins JJ, Pucilowska J, Lombardi RQ, Rooney JP: A mutation in a novel ATP-dependent Lon protease gene in a kindred with mild mental retardation. Neurology 2004; 63: 1927-1931.

10 Jaber L, Bailey-Wilson JE, Haj-Yehia M, Hernandez J, Shohat M: Consanguineous matings in an Israeli-Arab community. Arch Pediatr Adolesc Med 1994; 148: 412-415.

11 Jaber L, Halpern GJ, Shohat T: Trends in the frequencies of consanguineous marriages in the Israeli Arab community. Clin Genet 2000; 58: 106-110.

12 Zlotogora J: Genetic disorders among Palestinian Arabs: 1. Effects of consanguinity. Am J Med Genet 1997; 68: 472-475.

13 Basel-Vanagaite L, Attia R, Yahav M et al: The CC2D1A, a member of a new gene family with $\mathrm{C} 2$ domains, is involved in autosomal recessive nonsyndromic mental retardation. J Med Genet 2006; 43: $203-210$.

14 Shohat M, Frimer H, Shohat-Levy V et al: Prenatal diagnosis of Down syndrome: Ten year experience in the Israeli population. Am J Med Genet 2003; 122: 215-222.

15 Zlotogora J, Reshef N: Prenatal testing for genetic disorders among Arabs. Prenat Diagn 1998; 18: 219-224.

16 Jaber L, Dolfin T, Shohat T, Halpern GJ, Reish O, Fejgin M Prenatal diagnosis for detecting congenital malformations: acceptance among Israeli Arab women. Isr Med Assoc J 2000; 2: $346-350$.

17 Toledano-Alhadef $\mathrm{H}$, Basel-Vanagaite L, Magal $\mathrm{N}$ et al: Fragile X carrier screening and the prevalence of premutation and full mutation carriers in Israel. Am J Hum Genet 2001; 69: 351-360. 